Special Forum: Distance Learning

\title{
COVID-19 Response "Playbooks" at Boston University School of Theology Library
}

by Amy Limpitlaw, Stacey Duran, and Sean Smith

Librarians historically have had to adapt their services and offerings to changing circumstances. Usually, however, there is time to assess the changed landscape and implement changes gradually and after careful consideration. In Spring 2020, however, the unusual situation of a global pandemic forced librarians everywhere to quickly modify their services and implement what in many cases were radically new procedures and offerings. At the School of Theology Library of Boston University, such changes were decided upon and implemented literally in the space of six days.

While not having the advantage of time to carefully and judiciously decide on how to change its services, the staff members of the library were not without a foundation upon which to build. The library already had been purchasing e-books for its collection for many years. And a program for serving distance learners was already in place, having been implemented after the launch of the school's largely online Doctor of Ministry degree program. The task, then, became one of how to extend and, if needed, modify this foundation to respond to the new situation. In what follows, we will describe in more detail how the library staff worked collaboratively to implement various "playbooks" for serving patrons remotely during the pandemic.

\section{RECENT CHANGES TO E-BOOK COLLECTION POLICIES}

As noted, one of the foundations already in place prior to the crisis was the library's collection of e-books. Prior to 2012, the theology library did not have a policy in place for the selection and purchase of electronic books. When Amy Limpitlaw, the head librarian, broached the possibility of purchasing more of its collection in electronic format with faculty, the response she received was mixed. Some faculty expressed their dislike of e-books, expressing their strong preference for the physical print book. There was also concern about the stability of the medium and licensing. Taking these concerns into consideration, the head librarian worked with the faculty members serving on the Library Committee to create a policy for limited procurement of e-books (for example: only buying e-books if a physical copy was available locally, allaying concerns of faculty). The overall outcome was that, although the library did increase its collection of e-books, in many cases electronic was not the default or preferred medium and a large bulk of its collection remained in physical format, even when electronic could have been procured.

The move to a remote learning environment in mid-March revealed some of the shortcomings of this approach. While the number of e-books in the collection was not insignificant, many required texts for courses now being taught remotely were not available electronically. The staff quickly went to work to locate electronic versions of texts required for classes, as well as for texts being requested by students for research assignments. In addition to accelerating its purchase of e-books, the library also looked into the various offerings made by publishers, vendors, and other providers for temporary free access to electronic resources or discounted rates for e-books. For the most part, the staff quickly learned that it was simply easier for library staff to do the legwork to find

Amy Limpitlaw is Head Librarian, Stacey Duran is Instruction \& Collection Development Librarian, and Sean Smith is Outreach \& Public Services Librarian at Boston University. 
the desired e-book, rather than pointing students or faculty to the various places where they could search themselves, and so the library encouraged faculty and students to contact staff directly with their requests.

\section{EXISTING SERVICES TO OUR DISTANCE PROGRAM}

The second foundation already in place was the library's program of support for the school's single online degree program. When the school unveiled its first online degree-a hybrid online/on-site Doctor of Ministry program-in 2014, Stacey Duran, then the access services librarian, proposed a multi-layered response. The collection development policy was adjusted to prioritize e-books where possible for course readings. Reference services were expanded to include virtual reference via Skype and, as part of the library's ongoing personal librarian program, Duran volunteered to serve as permanent liaison to the program. As liaison, she coordinates library orientation and instruction sessions during the brief on-campus portions each semester, as well as screencasts of document delivery procedures and workshops that could be viewed remotely.

Access to library materials would be the most difficult part of the library's pandemic response, of course. Distance services for the Doctor of Ministry program relied heavily on reciprocal borrowing privileges through the Boston Theological Interreligious Consortium (BTI), Boston Library Consortium (BLC), and the fledgling Atla reciprocal borrowing program. However, the library also experimented with a back-up plan using document delivery (via mail) of books in addition to chapter and article scans.

\section{DEVELOPING “PLAYBOOKS” FOR RAPIDLY CHANGING CIRCUMSTANCES}

As the COVID-19 crisis deepened in early March 2020, careful planning for multiple contingencies and adaption of currently existing distance education infrastructure was vital for School of Theology Library services and support to keep pace successfully with the rapidly changing world. We defined "effective support" based on the following three factors: (1) continued (but safe) access to reference services, instruction, and librarians; (2) facilitating access to our collections, both physical and electronic, as safely as possible, and (3) clear, consistent communication with our community of users on how to access these services.

Library staff, led by Outreach and Public Services Librarian Sean Smith, began creating "playbooks" highlighting potential library services based on many different potential institutional-level responses to COVID-19 in early March, during the very early stages of the crisis, with clear checklists for implementation. This involved collaborative planning among staff for all possible contingencies, from implementation of basic physical distancing measures (e.g., adjusted circulation procedures and spacing of seating) to the seemingly slim chance of a shift to fully remote teaching for the remainder of the Spring 2020 semester. As circumstances rapidly changed, so did the look of library services: from business as usual, to open to the public limited hours with physical distancing protocols, to fully remote teaching (with a fully virtual library!), within the span of six days. A special, continually updated COVID-19 response page on the library's website, coupled with consistent communication with the community across all platforms, communicated these changes with our community. A key lesson learned from the COVID-19 pandemic is to expect rapid change during crises, and to anticipate and prepare for quick pivots. 
In conclusion, our "playbooks" for remote learning rely heavily on the use and expansion of the existing infrastructure serving our distance education community. Reference assistance continues virtually; library staff have significant experience with online instruction and screencasts for the distance education community. While the physical building may be closed, the library facilitates access to our physical collections via document delivery scans, a service not previously available to on-campus students. Instructions on utilizing document delivery already existed, needing only slight adaptation for our COVID-19 world. The distance education program provided a catalyst for our robust e-book purchasing program (including purchasing all course reserve material electronically, if available). To highlight these collections, staff created course guides for all Spring 2020 classes showing e-books related to each course, which were then shared with faculty and on course reserve lists. These and other adaptions of existing infrastructure facilitated quick implementation of our "playbooks" as the situation rapidly changed, as all students soon became "distance students." 